\title{
Notas SObre EL DaÑo MORAL: CONCEPTO, PRUEBa Y AVALUACIÓN EN UNA RECIENTE SENTENCIA DE LA CORTE de Apelaciones de Santiago
}

\author{
Hugo Cárdenas Villarreal ${ }^{1}$ \\ Paulina González Vergara ${ }^{2}$
}

A propósito de los 150 años de la promulgación del Código Civil nacional y de sus diversas celebraciones, mucho se ha hablado sobre la gran evolución sufrida por el Derecho Civil comparado y especialmente, aquella experimentada por la institución de la responsabilidad civil.

En Chile esta evolución ha sido más lenta que en otros sistemas, y por lo mismo, en muchos aspectos se encuentra recién en sus inicios. Sin embargo, no es posible dejar de reconocer el importante desarrollo que ha significado la recepción jurisprudencial del principio de la reparación integral del daño, en cuanto a la consideración del daño moral como categoría de daño indemnizable, frente a una mayor y más completa protección de la persona.

La sentencia comentada es una muy buena muestra de esta evolución. En ella se acoge expresamente tal principio, al cual cataloga como el fin de la responsabilidad civil, y el ideal que ha de ser perseguido por el juez en la determinación del daño y su avaluación, tanto en materia extracontractual como contractual; y por lo mismo, podría decirse que de cara al pasado representa la culminación de dicha evolución en nuestra jurisprudencia. Pero por otra parte, y ahora de cara al futuro, al referirse a cuestiones como el concepto de daño moral, su prueba y avaluación, alude a las que son las tareas pendientes en esta materia en el ámbito nacional.

Abogado. Doctorando en Derecho Pontificia Universidad Católica de Chile.

Abogada. Becaria MECESUP Doctoranda en Derecho Pontificia Universidad Católica de Chile. 


\section{LOS HECHOS}

La sentencia comentada se refiere a un caso de accidente de tránsito en que se ocasionó la muerte de la hija menor de catorce años de la demandante.

En ella se condena solidariamente al pago de la indemnización al conductor del camión y a su propietario. Respecto de este último, la sentencia considera legitimado pasivamente a quien aparece sindicado en tal calidad en la correspondiente inscripción en el Registro de Vehículos Motorizados, aun cuando se encuentra acreditado que existió una compraventa del vehículo, en tanto nunca se efectuó la nueva inscripción ni se realizó la entrega material.

\section{CONCEPTO DE DAÑO MORAL}

A pesar de que en el ámbito chileno sería prematuro afirmar en estos momentos que el daño moral no se identifica con el manoseado pretium doloris, sí puede observarse que la jurisprudencia de nuestros tribunales ha experimentado una evolución hacia las nuevas tendencias que, de hecho, han posibilitado un mejor desarrollo dogmático de la categoría en el derecho comparado. En efecto, la sentencia que comentamos constituye un claro ejemplo de lo que decimos, pues en la argumentación que efectúa el juzgador, si bien tiene presente que otras sentencias adhieren al concepto del pretium dolores, se decanta por el concepto que entiende al daño moral como un atentado contra los derechos de la personalidad (véase considerando $\left.n^{\circ} 7\right)^{3}$.

En este punto la evolución resulta más que considerable si se piensa que en Chile, la primera sentencia que reconoce el daño moral data de $1922^{4}$. Como se sabe, al no mencionar nuestro Código Civil el daño moral más que para negarlo (art. 2331 CC.), su acogida y posterior desarrollo solo podía ser llevado a cabo por la jurisprudencia que, en un primer momento lo rechazaba arguyendo la imposibilidad de apre-

3. Nótese que en el mismo considerando, la Corte admite sin reparos la procedencia de la indemnización del daño moral en materia contractual, lo que equivale sin duda, la evolución más trascendente que ha experimentado el sistema de responsabilidad civil chileno.

4 Aunque según Barros, la discusión no pasa de ser antecedente anecdótico, es de señalar que hay autores que sitúan el reconocimiento del daño moral en una sentencia de la Corte de Apelaciones de Santiago de 1907. Al parecer, la citada sentencia fue revocada y sustituida posteriormente por otra sentencia de la Corte de Apelaciones de Santiago, de 25 de octubre de 1911, en la que se desestimó la procedencia de la indemnización por daño moral. Sobre el rema puede verse, VICARI, Alejandro y UGARTE, Eduardo, Edición del curso de responsabilidad civil extracontractual del profesor Enrique Barros Bourie. Jurisprudencia y doctrina, Tesis de Licenciatura, Universidad de Chile, Santiago, 1999, p. 108 y ss. 
ciación económica de este tipo de perjuicios (clase de pensamiento que se acomodaba bien a la moral de la época, la cual no veía con buenos ojos el que las penas se enjuagaran con dinero).

Inicialmente, fue la sensibilidad ante el dolor ajeno la que propició la reparación de este tipo de perjuicio, razón por la cual y como no podría ser de otra manera, el daño moral fue conceptuado por la jurisprudencia y la doctrina nacional (siempre a la saga de la doctrina francesa) como el dolor, pesar o molestia que sufre una persona en su sensibilidad física, en sus sentimientos y afectos o en su calidad de vida: el pretium doloris ${ }^{5}$.

En el derecho comparado, en atención a potenciar la extensión de los perjuicios morales, el camino seguido fue el de brindar un concepto más amplio del daño moral, pues no cabía duda, de que entender el daño moral como el dolor o las molestias era un concepto que no permitía la consideración de ciertos aspectos de la persona cuyo detrimento o menoscabo no producen en puridad tormento o dolor. De esta manera, el daño moral o extrapatrimonial, deja de identificarse con el precio del dolor y se entiende como una categoría más general que engloba distintos tipos o categorías de daños extrapatrimoniales ${ }^{6}$.

Aunque con menos claridad que la deseable, la sentencia comentada asume un concepto amplio de daño moral, pues, concibe dentro de los perjuicios extrapatrimoniales, además del pretium doloris a otras categorías o tipos como la lesión a los derechos y bienes o atributos de la personalidad. De esta manera, se une a la que creemos es hoy la tendencia mayoritaria en nuestra jurisprudencia, para la cual el daño moral se identifica con la lesión a los intereses extrapatrimoniales, y nos permite observar, además del camino por recorrer, el notable avance que ha existido en esta materia.

\section{Prueba del daño moral}

Tanto la doctrina como la jurisprudencia mayoritaria en relación a la prueba del daño moral han sostenido desde hace largo tiempo, que

5 Entre los clásicos, Alessandri Rodríguez, Arturo, La responsabilidad civil extracontractual en el Derecho Civil chileno, Imprenta Universitaria, Santiago, 1943, p. 220 y ss.; Meza Barros, Ramón, Manual de Derecho Civil. De las fuentes de las obligaciones, t. II, $8^{\text {a }}$ ed., Ed. Jurídica, Santiago, 1998, p. 249. En la jurisprudencia pueden verse, entre otras muchas, Corte Suprema, sentencia de 10 de agosto de 1971 , en RDJ, t. 68, sec. $4^{2}$, p. 168; Corte de Apelaciones de Temuco, sentencia de 29 de junio de 1972, en RDJ, t. 69, sec. 4a, p. 374; Corte de Apelaciones de San Miguel, sentencia de 8 de agosto de de 1989 , en RDJ, t. 86 , sec. $4^{\text {a }}$, p. 73.

6 Sobre el tema puede verse, Domínguez Águila, Ramón, "Consideraciones en torno al daño en la responsabilidad civil. Una visión comparatista", en Revista de Derecho, $\mathrm{n}^{\circ} 188$, Universidad de Concepción, 1990, p. 136 y ss. 
a diferencia del daño material, este no necesita de ninguna clase de prueba $^{7}$.

En esta misma línea, la sentencia comentada establece que "El daño moral puro consistente en el menoscabo psíquico y el dolor causado a la madre por la muerte de su hija menor, no requiere de prueba alguna" (el destacado es nuestro).

Paulatinamente, esta posición ha comenzado a variar a partir de las críticas vertidas en la doctrina en cuanto a la injusticia a las que puede acarrear. En efecto, la ausencia de exigencias probatorias ha sido señalada como uno de los extremos pendientes de la teoría del daño moral en nuestro sistema ${ }^{8}$ y en este contexto, la sentencia comentada no se hace cargo de tales críticas y de la evolución jurisprudencial que se viene presentando en esta materia y se mantiene erróneamente en la doctrina más clásica al respecto.

Tímidamente se ha comenzado a abrir paso en nuestra jurisprudencia la posición que sostiene que el daño moral debe ser acreditado en el proceso mediante la aportación de pruebas que demuestren su existencia. Así se ha fallado que "Tampoco se ha probado en autos la concurrencia de daño moral, no siendo suficiente, a juicio del tribunal, su mera invocación, pues, incluso en su determinación, deben existir elementos objetivos que permitan relacionar el "sufrimiento" de quien lo alega, con los hechos que lo motivan, a fin de establecer la relación de causalidad correspondiente, elementos que, como se observa, no han sido debidamente acreditados." (Sentencia de Tribunal de letras de Arica, de fecha tres de julio de dos mil uno. Rol N ${ }^{\circ} 23.809-00$ )

Más allá de la afirmación general de la exigencia de prueba para el establecimiento de la existencia del daño moral, nuestra jurisprudencia ha comenzado, creemos acertadamente, ha establecer para estos efectos dos tipos de daños morales: a) aquellos cuya existencia puede presumirse; y b) aquellos cuya existencia debe ser acreditada mediante pruebas distintas a la de presunciones o no solo por estas.

En este sentido, se ha señalado que "Por último, no está de más hacer presente, en cuanto a la prueba del daño moral, que a pesar de que tanto la doctrina como la jurisprudencia mayoritaria coinciden en señalar que el daño moral no requiere prueba, que solo basta que la víctima acredite la lesión de un bien personal para que se infiera el daño; en este caso, que se trata de daños a una cosa corporal, no se puede presumir de ello el daño moral, entendido como "el dolor, pesar o molestia que sufre una persona en su sensibilidad física, en sus sen-

Por todos, Vicari, Alejandro y Ugarte, Eduardo, ob. citada p. 117 y sgtes. Con referencia a numerosa jurisprudencia.

8 Domínguez Hidalgo, Carmen, El daño moral, Ed. Jurídica de Chile, Santiago, p. 682-683. 
timientos o afectos o en su calidad de vida". Cierto es que otro tipo de lesiones a la integridad física o síquica permiten inferir el daño moral, pero en el caso de autos debió ser acreditado en cuanto a su existencia" (Sentencia del Tribunal de Letras de Antofagasta, de fecha treinta y uno de julio de dos mil dos, Rol No 39.010-01).

La tarea pendiente a este respecto es el desarrollo de la tipología de daños morales que pueden ser presumidos y aquellos que no, a partir de la determinación de grupos de casos, que permitan la aplicación de estas dos categorías de daños de una manera más uniforme y transparente, con miras a la reducción de la arbitrariedad que su utilización no fundamentada podría ocasionar. Y en todo caso, en el entendido por una parte, de que las circunstancias que sirven de base a la presunción de daños deben estar debidamente acreditadas en el proceso, y por otra, que en estos casos, ha de admitirse siempre prueba en contrario.

A este respecto, la jurisprudencia citada entrega dos pautas que podrían servir de fundamento a la determinación de algunos de los aludidos grupos de casos. Primero, daños morales que pueden ser inferidos a partir de ciertas lesiones a la integridad física o psíquica; y segundo, daños morales que, en cuanto son consecuencia de la afectación de cosas corporales, deben ser acreditados en el proceso mediante la aportación de pruebas.

En el contexto de esta distinción, la postura del sentenciador al señalar que el daño moral reclamado no requiere de prueba alguna no parece acertada. Se trataría más bien de uno de aquellos casos en que es posible presumir la existencia de este tipo de daño. Por cuanto, y aplicando reglas de experiencia, lo natural es que la muerte de un hijo ocasione, tal como señala la sentencia comentada, un menoscabo psíquico y dolor constitutivo de daño moral que ha de ser indemnizado.

\section{Criterios de avaluación del daño moral}

Es frecuente escuchar que nuestros tribunales de justicia sostienen la postura de que la determinación y avaluación del daño moral es una materia entregada a la completa libertad y discrecionalidad del juzgador $^{9}$, lo cual es fuertemente criticado como fuente de arbitrariedades. Y en este sentido, la sentencia comentada se hace cargo de tales críticas y acoge la evolución que a este respecto se ha venido produciendo en el derecho comparado y en nuestra doctrina, marcando un quiebre con la jurisprudencia anterior.

Luego de hacer presente la problemática en relación a la indemnización del daño moral, a partir de la imposibilidad natural de convertir este tipo de perjuicios directamente en unidades monetarias, y de

9 Por todos, Domínguez Hidalgo, Carmen. p. 679 y sgtes. 
referirse a la aludida posición tradicional (campo subjetivo-soberanía del juez exenta de sujeción a criterios objetivos); el sentenciador se pronuncia sobre la necesidad de que su determinación y avaluación debe estar regida por una serie de pautas o criterios que el juez ha de considerar, con el fin de reducir la arbitrariedad en la determinación de la correspondiente indemnización.

Las pautas o criterios mencionados como aquellos que deben regir la reparación del daño moral, son las siguientes: a) La reparación integral del daño; b) Evitar las indemnizaciones en globo y procurar una evaluación separada y fundamentada de cada una de las partidas de la indemnización; c) Creación de tablas o baremos para daños morales que permiten al juez un parámetro para fijar la indemnización; d) Consideraciones de carácter macro y macroeconómicas, es decir, el grado de desarrollo económico del país y la situación particular de la víctima y de la persona obligada; y e) Publicaciones periódicas de las indemnizaciones judiciales, con lo cual se consigue obtener una información estadística que en cierto modo sirva para uniformar las decisiones en casos semejantes.

En esta parte, en lo referido a la enunciación de los mencionados criterios o pautas, el sentenciador no nos da grandes sorpresas. Más bien, hace eco de aquellos que han sido enunciados y desarrollados por el derecho comparado (al que como no es usual, se refiere expresamente), y $\sin$ mayores aportes por nuestra doctrina. Sin embargo, creemos que su planteamiento resulta interesante en varios aspectos.

\section{a) En cuanto al fin de la responsabilidad civil y en especial, de la reparación del daño moral}

Como ya se hizo presente, la sentencia que comentamos acoge expresamente el principio de la reparación integral del daño, respecto del cual precisa que "constituye el fin último de la responsabilidad extracontractual y contractual, y como tal debe ser el ideal perseguido por el juez al determinar el resarcimiento del daño y el quantum de la indemnización".

De esta manera, en cuanto fin de la responsabilidad civil, este principio tendría como funciones, por una parte, propender a la reparación de todo tipo de daño. Específicamente, en materia de daño moral, tanto aquel de naturaleza extracontractual como el contractual, y de sus diversas clases o tipos (tipología de daños morales); y por otra, en relación a la determinación de la indemnización, como presupuesto de la fijación del quantum, en tanto consideración de la entidad o importancia del daño como su principal medida.

Hasta aquí, el sentenciador se mantiene en una posición no controvertida. Sin embargo, al agregar "Que para determinar el resarcimiento del daño y el quantum de la indemnización y dejando a un lado las 
discusiones dogmáticas respecto a que si la sanción civil del daño moral es una pena privada o es una reparación, simplemente debe recurrirse pragmáticamente, a todos los elementos que llevan a una indemnización que satisfaga la víctima"(el destacado es nuestro), la cuestión comienza a cambiar. Podría sostenerse que la sentencia comentada establece que la satisfacción de la víctima también es un fin de la responsabilidad civil, al menos en lo que a reparación de daños morales se refiere. Y ello con importantes consecuencias, permitiendo la introducción de criterios de avaluación tradicionalmente considerados como punitivos, y en cuanto tales, mayoritariamente rechazados por nuestra doctrina como ilegítimos ${ }^{10}$.

Así, resultaría que en nuestro sistema de reparación de daño moral encontraríamos junto al principio de la reparación integral, el de la satisfacción de la víctima, los cuales habrían de ser armonizados por el juez al determinar el monto de la correspondiente indemnización.

Aun cuando, la concreción de este principio es una cuestión pendiente, creemos que su consideración al permitir una mirada más atenta a la situación concreta de la víctima y en atención a la naturaleza especialísima del daño moral y de su reparación (compensación), podría resultar en una mayor vigencia o mejor cumplimiento de la función general pacificadora del Derecho y de la sentencia como su máxima expresión, respecto de esta clase de conflictos.

\section{b) En cuanto a la recepción de ciertas pautas o criterios de ava- luación considerados como punitivos}

Al contemplar criterios como la situación particular de la víctima y de la persona obligada el sentenciador introduce criterios considerados como punitivos y en cuanto tales, no admisibles a partir del reconocimiento como principio básico de la responsabilidad civil de que "la medida de la suma de dinero concedida a la víctima viene determinada única y exclusivamente por la entidad del perjuicio causado (todo el daño y nada más que el daño)"11.

Respecto a este punto, a la utilización de criterios punitivos, nos parece oportuno llamar la atención sobre dos aspectos.

Esta, aunque fuertemente criticada desde la doctrina, es usual entre nuestra jurisprudencia. Por cuanto, se suele acudir (ya sea de modo explícito o no) a criterios punitivos para la determinación del

10 Ibid, p. 679

11 Ibid p. 678-679. 
monto de la indemnización ${ }^{12}$ y no parece probable el abandono de su consideración. Así las cosas, creemos que su referencia expresa por los sentenciadores es elogiable y beneficiosa porque en definitiva, vuelve más transparente sus decisiones al dejar de manifiesto las verdaderas razones que las sustentan.

Por otra parte, y ligado con las ideas planteadas anteriormente, en cuanto a la búsqueda de la satisfacción de la víctima, creemos que es posible repensar la utilización de algunos de estos criterios.

Así, en relación a casos de responsabilidad del Estado (situación particular de la persona obligada) en que la condena a una elevada suma de dinero podría significar el uso de gran parte del presupuesto de un determinado servicio, con el perjuicio correspondiente al resto de los usuarios, y en tanto, la víctima se encuentre "satisfecha" (situación particular de la víctima) podría abrir paso a la posibilidad de otra clase de compensaciones (no dinerarias). De modo de armonizar los principios de reparación integral del daño y de satisfacción de la víctima con la posible afectación del principio de continuidad del servicio público que podría darse en estos casos.

\section{C) EN CUANTO a La ponderación de las pautas o CRITERIOS CONSIDERADOS, MÁS ALLÁ DE SU MERA ENUNCIACIÓN}

En esta materia la Corte simplemente señala que "Ponderando estos jueces estas variables ajustada al mérito de los autos fijarán una indemnización por daño moral que deberán pagar ... la suma de ..." sin expresar justificación alguna, más allá de la alusión general al mérito de los autos.

Si lo buscado es reducir efectivamente la arbitrariedad de modo que la determinación del monto de la indemnización por daño moral sea más transparente y fundamentada, no basta el señalamiento sin más de los criterios o pautas tomados en consideración, agregando que todos ellos fueron ponderados por el tribunal para arribar a su decisión. Se ha de explicitar el modo en que se ha efectuado tal operación, partiendo por señalar el peso específico o relevancia (y este es el sentido fundamental de ponderar: el de pesar) de cada uno de tales criterios o pautas en la determinación de la indemnización, aduciendo las razones que se han tenido para ello.

Establecer una jerarquía a priori entre los mismos, rígida y aplicable a todos los casos, no nos parece una solución acertada. En nuestro sistema, creemos más bien que a partir de la afirmación de que es la

12 Vicari, Alejandro y Ugarte, Eduardo, ob, cit, p. 117 y sgtes. Con referencia a numerosa jurisprudencia. 
entidad del daño causado la medida fundamental de la indemnización, y en atención a las consideraciones señaladas en el apartado anterior, se deben establecer aquellos grupos de casos en los cuales dicho criterio ha de ser armonizado con otros y en qué sentido.

\section{Comentarios finales}

Por último, en el contexto del Estado de Derecho y su fortalecimiento, específicamente desde la perspectiva de los principios del debido proceso y de interdicción de la arbitrariedad, no queremos dejar de hacer presente el esfuerzo justificatorio de la sentencia comentada.

Lo anterior, en tanto los aludidos principios implican la motivación legítima (juridicidad-racionalidad) de los actos de autoridad, en especial, de las sentencias judiciales, en dos sentidos. Primero, en cuanto a la existencia de tales motivos, y segundo, en cuanto a su manifestación expresa en el acto de que se trate. 